\title{
Phosphorus Adsorption Capacity Evaluation for the Substrates Used in Constructed Wetland Systems: a Comparative Study
}

\author{
Hongling Dai*, Fengping Hu \\ School of Civil Engineering, East China Jiaotong University, Nanchang 330013, P. R. China
}

Received: 2 August 2016

Accepted: 3 November 2016

\begin{abstract}
To provide a selection criteria to choose substrates according to the quality of the water requiring treatment in constructed wetlands $(\mathrm{CWs})$, phosphorus $(\mathrm{P})$ adsorption properties of four quartz sands with different physicochemical characteristics and four substrates commonly used in CWs were tested and evaluated via both the Langmuir and Freundlich equations. The effects of organic maters (OM) on $\mathrm{P}$ adsorption capacities of the substrates were also studied to evaluate the practical values of the substrates. The Langmuir sorption isotherm was used to estimate the $\mathrm{P}$ adsorption capacities of the tested substrates in CWs. Overall, the maximum P adsorption for all of the tested substrates decreased as follows: furnace slag $>$ ceramic $>$ zeolite $>$ activated carbon $>$ quartz quartz sands. The P adsorption capacities were significantly influenced by grain size; specific surface area; $\mathrm{Fe}, \mathrm{Al}, \mathrm{Mg}$, and $\mathrm{Ca}$ contents in the substrates; and the amount of added OM. The chemical precipitation of $\mathrm{P}$ by the substrates containing Fe was more effective than those containing $\mathrm{Ca}$ at the same level. Added $\mathrm{OM}$ impacts $\mathrm{P}$ sorption by influencing $\mathrm{pH}$, and substrates containing higher $\mathrm{Fe}$ and $\mathrm{Al}$ concentrations and lower $\mathrm{Ca}$ concentrations were more resistant to decreases in the $\mathrm{P}$ adsorption capacities due to OM accumulation. Finally, a principle for selecting substrates for the treatment of wastewater with different characteristics was determined.
\end{abstract}

Keywords: Phosphorus adsorption, substrates, Langmuir adsorption isotherm, Freundlich adsorption isotherm, organic maters $(\mathrm{OM})$

\section{Introduction}

CWs have been designed and constructed to use natural processes for the removal of pollutants from contaminated water in a more controlled environment [1-3]. Previous results have shown that substrate adsorption plays the most important role in P immobilization [4-8]. Therefore, cheap and effective $\mathrm{P}$ adsorbents are highly desirable [9-11].

*e-mail: hldai_water@126.com
The most commonly used substrates in CWs are quartz sands [12], activated carbon (AC) [12-13], zeolite [14], ceramic [15], and furnace slag [16-17], and prior research has shown that the removal of $\mathrm{P}$ by these substrates mainly occurs though physical adsorption, chemical precipitation, and ion exchange [10-11]. However, P sorption properties of the substrates have not been systematically estimated, which resulted in many defective packing layer designs for CWs [3, 11]. Thus, it is important to evaluate the $\mathrm{P}$ adsorption properties of the substrates before full-scale use was performed. 
The Langmuir isotherm is a physical adsorption model that was calculated on the basis of assuming the adsorbed gas form monomolecular layer on a uniform surface [1819]. The greatest advantage of the application of Langmuir in adsorption study is that it enables the estimate of the theoretical $\mathrm{P}$ adsorption maximum of a substrate $[9,20]$. The Freundlich equation was also developed to evaluate adsorption performance. Unlike the Langmuir equation, the Freundlich equation is a physical-chemical adsorption model developed based on both physical adsorption and chemical adsorption via reaction or iron exchange [18, 20]. Thus, the P sorption capacity of substrates should be evaluated using both the Langmuir and the Freundlich equations.

The functions of CWs for treating wastewater largely depend on the accumulation, cycling, and decomposition of $\mathrm{OM}$, and $\mathrm{OM}$ accumulation is a typical feature of CWs [3, 10]. However, the accumulation of $\mathrm{OM}$ could potentially contribute to the pore clogging of the substrates [10], which reduces the substrate-flow in CWs and may decrease the hydraulic retention time (HRT) and $\mathrm{P}$ and $\mathrm{N}$ removal efficiency. Therefore, it is also important to experimentally investigate the impacts of $\mathrm{OM}$ on $\mathrm{P}$ sorption to evaluate the practical values of the substrates.

To provide a selection criteria that can be used to choose substrates according to the quality of the water requiring treatment in CWs, $\mathrm{P}$ sorption properties of four quartz sands with different physicochemical characteristics and four other substrates commonly used in CWs were tested and evaluated using both the Langmuir and the Freundlich equations in the present study. The effects of OM on the P sorption capacities of the substrates were also studied to evaluate the practical values of the substrates.

\section{Materials and Methods}

\section{The Tested Substrates}

Eight substrates that are frequently applied in CWs were chosen: four types of quartz sands, furnace slag, zeolite, ceramic, and AC. The four types of quartz sands were chosen for the present study to investigate the impacts of particle size and the chemical characteristics of substrates on P adsorption (I and II had nearly the same particle size distribution and different chemical characteristics; II and III had nearly the same chemical characteristics and different particle size distributions; and I and IV had nearly the same particle size distribution and chemical characteristics with different $\mathrm{Fe}$ and $\mathrm{Ca}$ contents, although the total $\mathrm{Fe}$ and $\mathrm{Ca}$ contents were nearly equal). The furnace slag used in this study was produced by steel mills. Furnace slag, zeolite, ceramic, and AC have been commonly used to enhance the contaminant removal capabilities of CWs. Elemental distribution, $\mathrm{pH}$, and particle size distribution of the substrates are shown in Tables 1 and 2.
Table 1. Chemical characteristics of the substrates.

\begin{tabular}{|c|c|c|c|c|c|}
\hline Materials & $\begin{array}{c}\mathrm{Fe} \\
\left(\mathrm{g} \mathrm{kg}^{-1}\right)\end{array}$ & $\begin{array}{c}\mathrm{Ca} \\
\left(\mathrm{g} \mathrm{kg}^{-1}\right)\end{array}$ & $\begin{array}{c}\mathrm{Al} \\
\left(\mathrm{g} \mathrm{kg}^{-1}\right)\end{array}$ & $\begin{array}{c}\mathrm{Mg} \\
\left(\mathrm{g} \mathrm{kg}^{-1}\right)\end{array}$ & $\mathrm{pH}$ \\
\hline $\begin{array}{c}\text { Quartz } \\
\text { sand I }\end{array}$ & 3.34 & 56.4 & 1.34 & 1.26 & 7.38 \\
\hline $\begin{array}{c}\text { Quartz } \\
\text { sand II }\end{array}$ & 2.27 & 35.4 & 1.51 & 1.12 & 7.08 \\
\hline $\begin{array}{c}\text { Quartz } \\
\text { sand III }\end{array}$ & 2.65 & 37.6 & 1.45 & 1.39 & 7.19 \\
\hline $\begin{array}{c}\text { Quartz } \\
\text { sand IV }\end{array}$ & 12.31 & 47.3 & 1.37 & 1.65 & 7.61 \\
\hline AC & - & - & - & - & 6.95 \\
\hline Zeolite & 15.1 & 12.3 & 71.6 & 3.14 & 10.4 \\
\hline Ceramic & 1.32 & 22.7 & 82.8 & 1.39 & 9.84 \\
\hline Furnace slag & 19.4 & 15.66 & 38.8 & 0.41 & 12.1 \\
\hline
\end{tabular}

Table 2. Grain size distribution of each candidate substrate (mass fraction/\%).

\begin{tabular}{|c|c|c|c|c|}
\hline Substrates & $\begin{array}{c}0.0-0.5 \\
\mathrm{~mm}\end{array}$ & $\begin{array}{c}0.5-1.0 \\
\mathrm{~mm}\end{array}$ & $\begin{array}{c}1.0-2.0 \\
\mathrm{~mm}\end{array}$ & $\begin{array}{c}2.0-5.0 \\
\mathrm{~mm}\end{array}$ \\
\hline Quartz sand I & 19.1 & 47.7 & 22.8 & 10.4 \\
\hline Quartz sand II & 19.6 & 50.1 & 18.7 & 11.6 \\
\hline Quartz sand III & 13.9 & 15.0 & 27.7 & 43.4 \\
\hline Quartz sand IV & 18.5 & 46.3 & 22.7 & 12.5 \\
\hline AC & 0.0 & 0.0 & 67.1 & 32.9 \\
\hline Zeolite & 0.0 & 0.9 & 58.1 & 41.0 \\
\hline Ceramic & 0.0 & 1.5 & 43.0 & 55.5 \\
\hline Furnace slag & 5.9 & 7.9 & 34.3 & 61.9 \\
\hline
\end{tabular}

\section{P Adsorption Experiment for the Substrates}

Equilibrium adsorption experiments were conducted for all of the chosen substrates. $4 \mathrm{~g}$ of each dried (at $105^{\circ} \mathrm{C}$ for $2 \mathrm{~h}$ ) substrate was settled into $100 \mathrm{~mL}$ centrifuge tubes containing $80 \mathrm{~mL} \mathrm{NaCl}$ solution $\left(0.05 \mathrm{~mol} \mathrm{~L}^{-1}\right)$ prepared in deionized water with $\mathrm{NaH}_{2} \mathrm{PO}_{4}(\mathrm{pH} 7.0 \pm 0.1)$ at $\mathrm{P}$ concentrations of $50,100,200,300,400,600$, 800 , and $1,000 \mathrm{mg} \mathrm{L}^{-1}$ for the ceramic, zeolite $\mathrm{AC}$ and furnace slag, and AC, and 5, 10, 20, 30, 40, 60, 80, and $100 \mathrm{mg} \mathrm{L}^{-1}$ for the quartz sands. The centrifuge tubes without substrate were used as a blank control group, and $0.5 \mathrm{~mL}$ of chloroform was added to all the tubes as bacterial inhibitor. The tubes were sealed and shaken using a constant temperature shaker for $24 \mathrm{~h}\left(165 \mathrm{rpm}, 25^{\circ} \mathrm{C}\right)$, and samples were taken and centrifuged for $15 \mathrm{~min}$ at 4,500 rpm. Then the supernatant solutions were filtered through $0.45 \mu \mathrm{m}$ filters, and the $\mathrm{P}$ concentrations were determined, and the $\mathrm{P}$ concentrations in the supernatant solutions were determined. Three parallel measurements 
were performed for each sample, and the mean and limits of error were also determined. The Langmuir and Freundlich equations were simultaneously used to determine the relationship between the $\mathrm{P}$ adsorption capacity of the substrates and the $\mathrm{P}$ concentration in the equilibrium solutions. The Langmuir equation is defined as follows:

$$
q=a b \rho_{e} /\left(1+b \rho_{e}\right)
$$

... and the Freundlich equation can be written as

$$
\mathrm{q}=k \rho_{\mathrm{e}}{ }^{1 / \mathrm{n}}
$$

...where $q$ is amout of adsorbed $\mathrm{P}\left(\mathrm{mg} \mathrm{g}^{-1}\right), \rho_{e}$ is the concentration of $\mathrm{P}$ in the solution at equilibrium ( $\left.\mathrm{mg} \mathrm{L}^{-1}\right)$, $a$ is the apparent $\mathrm{P}$ adsorption capacity $\left(\mathrm{mg} \mathrm{g}^{-1}\right), b$ is a constant related to the binding strength of $\mathrm{P}$, and $k$ is the apparent sorption rate constant. All data processing was conducted using DPS software [21].

\section{Impacts of OM on P Sorption}

Peat purchased from the local plant market had TC content of $499.7 \pm 9.1 \mathrm{~g} \mathrm{~kg}^{-1}$, and $\mathrm{pH}$ of $5.93 \pm 0.20$ was used as OM. The relative influences of $\mathrm{OM}$ on the sorption capacities of the substrates were investigated by mixing peat with the furnace slag, ceramic, zeolite, and $\mathrm{AC}$ because they are commonly used to enhance the process capacity of CWs. Five peat amendment levels were used $(0 \%, 4 \%, 8 \%, 12 \%$, and $16 \%$ of total weight of the mixtures), with triplicate samples for each level. First, the mixtures were dried at $105^{\circ} \mathrm{C}$ for $2 \mathrm{~h}$, then $5 \mathrm{~g}$ of each mixture were placed in $250 \mathrm{~mL}$ Erlenmeyer glass flasks. A $500 \mathrm{mg} \mathrm{kg}^{-1} \mathrm{P}$ solution was prepared in deionized water and amended with furnace slag, ceramic, zeolite, and AC. Then $1 \mathrm{~mL}$ of chloroform was added. The flasks were sealed and settled in a constant temperature shaker for $48 \mathrm{~h}\left(165 \mathrm{rpm}, 25^{\circ} \mathrm{C}\right)$. Samples were taken and centrifuged, and aliquots of the supernatant solutions were filtered through $0.45 \mu \mathrm{m}$ filters, and the $\mathrm{P}$ concentrations and $\mathrm{pH}$ of the filtered solutions were determined.

\section{Analytical Methods}

TC content of the peat was determined using a TOC analyzer [22], and the $\mathrm{pH}$ values of the substrates were detected by a $\mathrm{pH}$ meter in a 2.5:1 (volume ratio) water/substrate mixture after 24 hours' equilibration. $\mathrm{P}$ concentrations were measured by the molybdenum blue method with a total phosphorus analyzer, and $\mathrm{P}$ removed by the substrate was calculated as a decrease in the $\mathrm{P}$ concentration in the solutions. The experimental $\mathrm{pH}$ variations were determined using a $\mathrm{pH}$ probe. The $\mathrm{Fe}, \mathrm{Ca}$, $\mathrm{Al}$, and $\mathrm{Mg}$ contents in the substrates were analyzed via an atomic absorption spectrophotometer after being extracted in boiling $\mathrm{HNO}_{3}-\mathrm{H}_{2} \mathrm{O}_{2}[23]$.

\section{Results and Discussion}

\section{P Adsorption Capacities of the Substrates}

The relationships between the equilibrium $\mathrm{P}$ concentrations in solution and the amounts of $\mathrm{P}$ adsorbed for different substrates are shown in Fig. 1. The apparent $\mathrm{P}$ adsorption capacities of the substrates were estimated
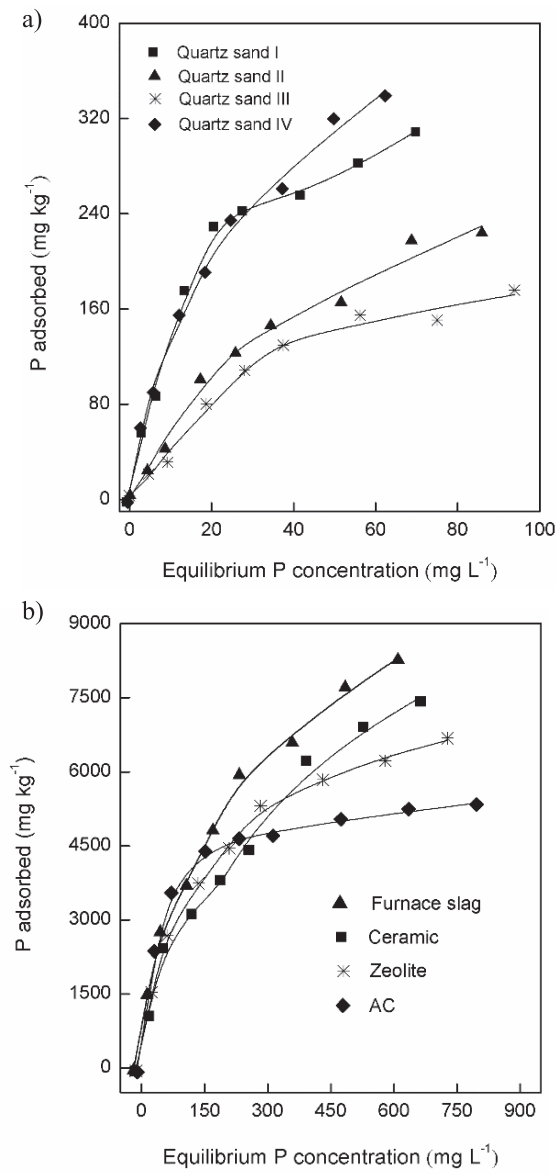

Fig. 1. Relationship between equilibrium a) P concentration and b) the $\mathrm{P}$ adsorbed.

Table 3. Langmuir sorption isotherm coefficients for the tested substrates.

\begin{tabular}{|c|c|c|}
\hline Substrates & $\begin{array}{c}\text { P sorption } \\
\text { maximum }\left(\mathrm{g} \mathrm{kg}^{-1}\right)\end{array}$ & Binding energy \\
\hline Quartz sand I & $0.30 \pm 0.02$ & $0.019 \pm 0.001$ \\
\hline Quartz sand II & $0.21 \pm 0.01$ & $0.027 \pm 0.002$ \\
\hline Quartz sand III & $0.18 \pm 0.01$ & $0.048 \pm 0.002$ \\
\hline Quartz sand IV & $0.33 \pm 0.03$ & $0.035 \pm 0.002$ \\
\hline AC & $4.64 \pm 0.05$ & $0.017 \pm 0.001$ \\
\hline Zeolite & $6.78 \pm 0.09$ & $0.031 \pm 0.002$ \\
\hline Ceramic & $7.24 \pm 0.12$ & $0.022 \pm 0.001$ \\
\hline Furnace slag & $8.11 \pm 0.10$ & $0.024 \pm 0.003$ \\
\hline
\end{tabular}


using the linear form of the Langmuir equation and is shown in Table 3. Preliminary experiments showed that the furnace slag, ceramic, zeolite, and AC adsorbed almost all of the $\mathrm{P}$ in the solution during a short period when $\mathrm{P}$ concentration was below $100 \mathrm{mg} \mathrm{L}^{-1}$, which was not observed in the quartz sands treatments. Therefore, two series of $\mathrm{P}$ solutions were used. As shown in Fig. 1 , the quantities of $\mathrm{P}$ adsorbed by the substrates were significantly varied when plotted as a function of the $\mathrm{P}$ concentration in the equilibrium solutions. The Langmuir adsorption maximums, as well as the binding energies, also varied significantly. The $\mathrm{P}$ adsorption maximums varied between $8.11 \pm 0.10 \mathrm{~g} \mathrm{~kg}^{-1}$ for the slag and $0.18 \pm 0.01$ for quartz sand III (Table 3 ). The maximum $\mathrm{P}$ adsorptions of the four quartz sands increased as follows: quartz sand III < quartz sand II < quartz sand I < quartz sand IV. Overall, the maximum P sorption for all of the tested substrates increased as follows: quartz sands (III $<$ II $<$ I $<$ IV) $<$ activated carbon $<$ zeolite $<$ ceramic $<$ furnace slag. The results of the present study demonstrated that the $\mathrm{P}$ adsorption capacities of substrates vary significantly; these findings are comparable with those reported in the literature [12, 24-26].

$\mathrm{P}$ adsorption capacity of quartz sand II was higher than quartz sand III (Fig. 1) because quartz sand II had a finer grain size (Table 1). The $\mathrm{P}$ adsorption capacities were impacted by the grain size of substrates because the substrates with fine grain sizes had larger specific surface areas, which can potentially enhance the $\mathrm{P}$ sorption capacity. Previous studies have also shown that $\mathrm{Al} / \mathrm{Fe}-$ bound $\mathrm{P}$ is correlated significantly with a proportion of the fine fraction [27]. P sorption capacities were also impacted by the chemical characteristics of the substrates because $\mathrm{P}$ could be precipitated when reacted with ionic $\mathrm{Fe}, \mathrm{Ca}, \mathrm{Al}$, or Mg [10, 28-29]. Studies by David [30] and $\mathrm{Xu}$ et al. [10] also showed that the P removal efficiency and sorption capacity are significantly affected by the Fe, $\mathrm{Ca}, \mathrm{Al}$, and $\mathrm{Mg}$ contents. In this study, $\mathrm{t}$ the $\mathrm{P}$ adsorption capacities of the quartz sands (I, II-IV) were positively correlated with the $\mathrm{Fe}$ and $\mathrm{Ca}$ contents. The differences between quartz sand I and quartz sand IV regarding their $P$ sorption capacity also indicated that the enhancement of $\mathrm{Fe}$ on $\mathrm{P}$ sorption was stronger than that of $\mathrm{Ca}$ at the same concentrations (Fig. 1 and Table 1). Fe extraction using ammonium oxalate from solution was also found to be a good indicator of $\mathrm{P}$ adsorption via ionic $\mathrm{Fe}$ [31]. Thus, more dissolved Fe would result in more $\mathrm{P}$ precipitation and is related to higher total amounts of $\mathrm{Fe}$ in the substrates [32]. Furnace slag also resulted in a higher $\mathrm{P}$ sorption capacity than ceramic (Table 3 ) because of the higher Fe content (Table 1). When comparing the adsorption isotherms of $\mathrm{AC}$, zeolite, and ceramic, the substrate with the highest specific surface area (AC) was quickly saturated and had a higher $\mathrm{P}$ sorption rate. However, the substrates with much lower specific surface areas and higher $\mathrm{Fe}, \mathrm{Ca}, \mathrm{Al}$, and $\mathrm{Mg}$ contents become saturated slowly, although they eventually reached a higher $\mathrm{P}$ sorption capacity because releasing metallic ions and $\mathrm{P}$ precipitation were much slower than physical adsorption [28, 31]. As shown in Fig. 1 and Table 3, the furnace slag exhibited a relatively higher $\mathrm{P}$ adsorption capacity than the quartz sands, ceramic, zeolite, and $\mathrm{AC}$, with a $\mathrm{P}$ sorption maximum of $8.11 \pm 0.10 \mathrm{~g} \mathrm{~kg}^{-1}$.

\section{Adsorption Isotherm}

Based on the results of the $\mathrm{P}$ adsorption experiment, the Langmuir and Freundlich equations were simultaneously used to examine the relationship between $\mathrm{P}$ adsorption capacities of the substrates and $\mathrm{P}$ concentrations in the equilibrium solutions. The correlation coefficients $\left(R^{2}\right)$ and other reaction constants are shown in Tables 4 and 5 .

Tables 4 and 5 show that the Langmuir and Freundlich adsorption equations both provide a good relationship between the equilibrium $P$ concentrations in solution and the amounts of $\mathrm{P}$ adsorbed for different substrates; the $R^{2}$ were $0.655-0.992$. However, the $R^{2}$ of the substrates based on the same adsorption equation varied. For example, the $R^{2}$ of quartz sand II, AC, and zeolite based on the Langmuir adsorption equation were 0.911-0.992, whereas for quartz sands I and III-IV, ceramic, and furnace slag, the values were $0.811-0.876$. The $R^{2}$ calculated for the Langmuir adsorption equation decreased as follows: AC $>$ zeolite $>$ quartz sand II $>$ quartz sand III $>$ quartz sand I $>$ ceramic $>$ furnace slag $>$ quartz sand IV. The $R^{2}$ for the same substrates but with different adsorption

Table 4. P adsorption model and related parameters of the substrates based on the Langmuir equation.

\begin{tabular}{|c|c|c|c|c|}
\hline Substrates & Langmuir adsorption isotherm & Correlation coefficient $\left(R^{2}\right)$ & $a /\left(\mathrm{g} \mathrm{kg}^{-1}\right)$ & $b$ \\
\hline Quartz sand I & $q=0.00570 \rho_{\mathrm{e}} /\left(1+0.019 \rho_{\mathrm{e}}\right)$ & 0.828 & 0.30 & 0.019 \\
\hline Quartz sand II & $q=0.00567 \rho_{\mathrm{e}} /\left(1+0.027 \rho_{\mathrm{e}}\right)$ & 0.911 & 0.21 & 0.027 \\
\hline Quartz sand III & $q=0.00864 \rho_{\mathrm{e}} /\left(1+0.048 \rho_{\mathrm{e}}\right)$ & 0.876 & 0.18 & 0.048 \\
\hline Quartz sand IV & $q=0.01155 \rho_{\mathrm{e}} /\left(1+0.035 \rho_{\mathrm{e}}\right)$ & 0.811 & 4.64 & 0.33 \\
\hline AC & $q=0.07881 \rho_{\mathrm{e}} /\left(1+0.017 \rho_{\mathrm{e}}\right)$ & 0.992 & 6.78 & 0.031 \\
\hline Zeolite & $q=0.2105 \rho_{\mathrm{e}} /\left(1+0.031 \rho_{\mathrm{e}}\right)$ & 0.901 & 7.24 & 0.022 \\
\hline Ceramic & $q=0.1590 \rho_{\mathrm{e}} /\left(1+0.022 \rho_{\mathrm{e}}\right)$ & 0.816 & 8.11 & 0.024 \\
\hline Furnace slag & $q=0.1955 \rho_{\mathrm{e}} /\left(1+0.024 \rho_{\mathrm{e}}\right)$ & 0.815 & & \\
\hline
\end{tabular}


Table 5. $\mathrm{P}$ adsorption model and related parameters of the substrates based on the Freundlich equation.

\begin{tabular}{|c|c|c|c|}
\hline Substrates & $\begin{array}{c}\text { Freundlich } \\
\text { adsorption isotherm }\end{array}$ & $R^{2}$ & $n$ \\
\hline Quartz sand I & $q=0.0107 \rho_{\mathrm{e}}^{0.730}$ & 0.833 & 1.37 \\
\hline Quartz sand II & $q=0.0197 \rho_{\mathrm{e}}^{0.535}$ & 0.797 & 1.87 \\
\hline Quartz sand III & $q=0.0225 \rho_{\mathrm{e}}^{0.439}$ & 0.831 & 2.28 \\
\hline Quartz sand IV & $q=0.0310 \rho_{\mathrm{e}}^{0.602}$ & 0.874 & 1.66 \\
\hline AC & $q=0.0660 \rho_{\mathrm{e}}^{0.402}$ & 0.655 & 2.49 \\
\hline Zeolite & $q=0.0324 \rho_{\mathrm{e}}^{0.469}$ & 0.839 & 2.13 \\
\hline Ceramic & $q=0.0655 \rho_{\mathrm{e}}^{0.465}$ & 0.830 & 2.15 \\
\hline Furnace slag & $q=0.0451 \rho_{\mathrm{e}}^{0.676}$ & 0.907 & 1.48 \\
\hline
\end{tabular}

equations were also different. For example, for $\mathrm{AC}$ and furnace slag the $R^{2}$ calculated via the Langmuir adsorption equation were 0.992 and 0.815 , respectively, whereas the values were 0.655 and 0.907 when calculated based on the Freundlich adsorption equation. The $R^{2}$ calculated using the Freundlich adsorption equation decreased as follows: furnace slag $>$ quartz sand IV $>$ quartz sand I $>$ zeolite $>$ quartz sand III $>$ ceramic $>$ quartz sand II $>$ AC.

The Langmuir isotherm is a physical adsorption model that was calculated on the basis of assuming that the adsorbed gas forms the monomolecular layer on a uniform surface [18-19], which indicates that the $\mathrm{P}$ adsorption isotherm of the substrates with finer grain sizes or higher specific surface areas could be more properly fitted by the Langmuir than the Freundlich equation. Thus, the $R^{2}$ of quartz sand II was higher than that of quartz sand III when fitted using Langmuir due to its finer grain size, and the $R^{2}$ for $\mathrm{AC}$ was the highest among the tested substrates because it had the highest specific surface area (Table 1). Furthermore, the Freundlich equation is a physicalchemical adsorption model developed based on both physical adsorption and chemical adsorption by reaction or iron exchange $[18,20]$; thus, the $\mathrm{P}$ adsorption isotherm of the substrates with higher $\mathrm{Fe}, \mathrm{Ca}, \mathrm{Al}$, and $\mathrm{Mg}$ contents could be better fitted by the Freundlich equation. As a result, the $\mathrm{R}^{2}$ value of quartz sand I when fitted with the Freundlich equation was higher than that of quartz sand II due to its higher Ca content, and $\mathrm{AC}$ had a lower $R^{2}$ value than zeolite, ceramic, and furnace slag due to the absence of $\mathrm{Fe}, \mathrm{Ca}, \mathrm{Al}$, and $\mathrm{Mg}$ (Table 2). Comparing the chemical composition and the $R^{2}$ of quartz sand I and IV, it was found that they had nearly equal $\mathrm{Fe}$ and $\mathrm{Ca}$ content sums, although quartz sand IV had a higher Fe content and lower Fe content than quartz sand $\mathrm{I}$ (the $\mathrm{Fe}$ and $\mathrm{Ca}$ contents of quartz sand I were $3.36 \mathrm{~g} \mathrm{~kg}^{-1}$ and $56.4 \mathrm{~g} \mathrm{~kg}^{-1}$, while that for quartz sand IV were $12.31 \mathrm{~g} \mathrm{~kg}^{-1}$ and $47.4 \mathrm{~g} \mathrm{~kg}^{-1}$ ). Tables 4 and 5 show that the $R^{2}$ value of quartz sand IV was higher and lower than that of quartz sand I when fitted using the Freundlich and Langmuir equations, respectively, indicating that the chemical precipitation of $\mathrm{P}$ by the substrates containing $\mathrm{Fe}$ was more effective than those containing $\mathrm{Ca}$ at the same content. This finding also explains the difference in $R^{2}$ between ceramic and zeolite when fitted by the different adsorption equations.

\section{Effects of OM on P Adsorption Capacitied of the Substrates}

In all the treatments, adding OM (peat) decreased the $\mathrm{pH}$ of the solutions because the $\mathrm{pH}$ of $\mathrm{OM}$ is $5.93 \pm 0.20$. The $\mathrm{pH}$ increased with time and then remained steady (Fig. 2). The $\mathrm{pH}$ of the $\mathrm{AC}$ remained steady only after $4 \mathrm{~h}$, and the $\mathrm{pH}$ of the other substrates remained steady after $8 \mathrm{~h}$. For example, when the amount of OM rose $(0 \%$ to $16 \%), \mathrm{pH}$ in the solution in slag treatment decreased (12.23 to 8.86), and $\mathrm{pH}$ of the solutions in ceramic and zeolite treatment decreased from 9.83 to 7.27 and from 10.4 to 7.67 , respectively. The AC treatment significantly varied $(p<0.05)$ with the rising OM concentration, and $\mathrm{pH}$ in the ceramic, zeolite, and furnace slag treatment decreased more significantly $(p<0.05)$ in the low $(0 \%$ to $8 \%$ ) than in the high ( $8 \%$ to $16 \%$ ) OM treatments. P removal efficiency of AC was significantly inhibited $(p<0.01)$ when the OM content rose from $0 \%$ to $16 \%$. However, the P removal efficiencies of the furnace slag and ceramic were significantly inhibited $(p<0.05)$ at higher OM contents, while that of the zeolite was only significantly inhibited $(p<0.05)$ at lower OM contents $(0 \%$ to $8 \%$ ).

OM accumulations were common in both the natural wetlands and the CWs [11, 33-34]. Moshi et al. [35] and Christoph and Klaus [36] showed that P adsorption was inhibited by OM. Furthermore, Erich et al. [37] provided the following theories: 1) OM competes for sorption sites, 2) OM can release previously adsorbed $\mathrm{P}$, and 3) $\mathrm{OM}$ can reduce the electrostatic attraction between the sorption sites and P. However, the present study verified that $\mathrm{P}$ adsorption capacities of the substrates could also be affected by $\mathrm{pH}$, which could be influenced by added OM. Gray et al. [38] reported that $\mathrm{P}$ sorption is decreased due to substrates with greater amounts of $\mathrm{Ca}$ at lower $\mathrm{pH}$ values, and becomes higher at lower $\mathrm{pH}$ due to substrates with greater amounts of $\mathrm{Al}$ and Fe. Ann et al. [24] and Ugurlu and Salman [29] also reported that the precipitation of $\mathrm{Al} \mathrm{P}$ and ferric $\mathrm{P}$ may increase at lower $\mathrm{pH}$ values, and lower $\mathrm{pH}$ values would result in lower dissolved $\mathrm{Ca}$ and $\mathrm{Mg}$. The constant decreases in the P sorption capacities of the tested substrates at lower OM contents were mainly attributed to lower dissolved $\mathrm{Ca}$ concentrations at low $\mathrm{pH}$ and the theories presented by Erich et al. [37]. However, for the zeolite, ceramic, and furnaces slag substrates, the significant $(p<0.05)$ decreases in $\mathrm{P}$ sorption of furnace slag and ceramic at high OM contents (16\%) and slight $(p<0.05)$ decreases in P sorption of ceramic could only be attributed to higher $\mathrm{Al}$ and $\mathrm{Fe}$ dissolution at lower $\mathrm{pH}$. $\mathrm{P}$ sorption efficiency significantly decreased when the OM content was high (16\%) because of the higher equilibrium $\mathrm{pH}$, which was not low enough for $\mathrm{Fe}$ and $\mathrm{Al}$ dissolution $[24,38]$. Thus, the P sorption capacities of the substrates 

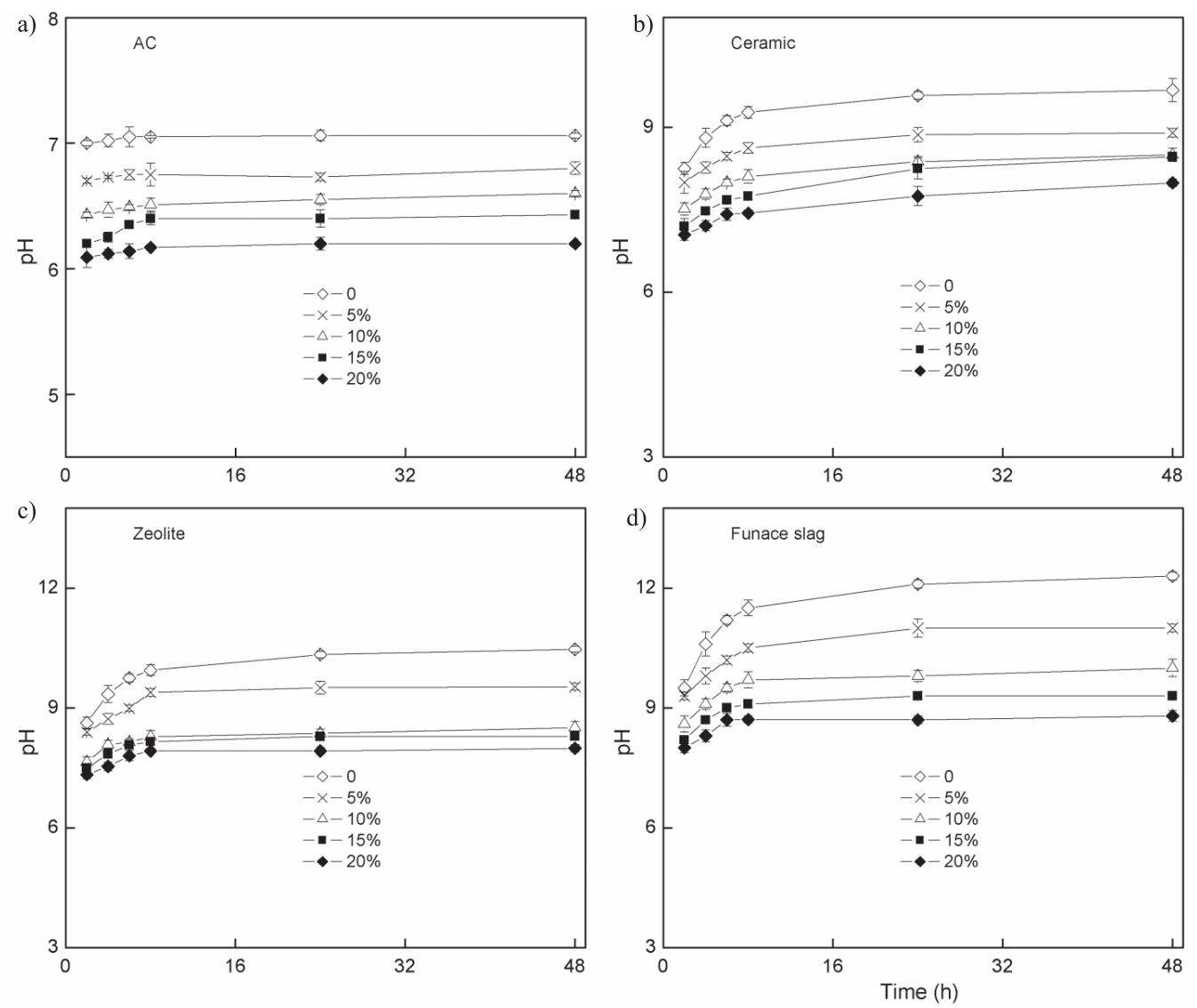

Fig. 2. Changes in $\mathrm{pH}$ with the $\mathrm{OM}$ levels.
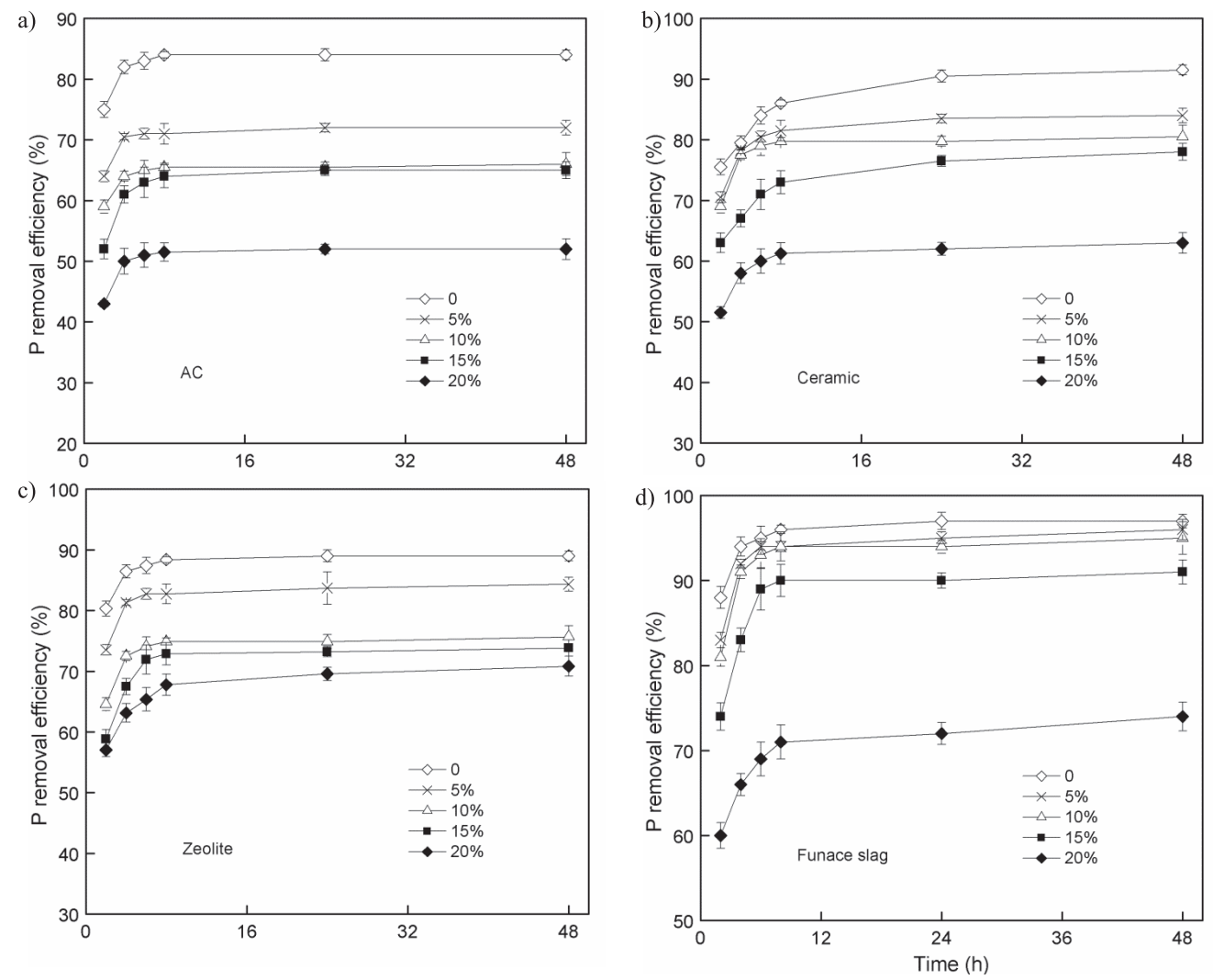

Fig. 3. Changes in P removal with OM levels. 
Table 6. The proper selection of the substrates for treatment of wastewater with different characteristics.

\begin{tabular}{|c|c|c|c|c|c|}
\hline \multirow{2}{*}{$\begin{array}{c}\text { The proper } \\
\text { substrates }\end{array}$} & \multicolumn{5}{|c|}{ Characteristics of the wastewater } \\
\cline { 2 - 6 } & P concentration $\downarrow^{\mathrm{a}}, \mathrm{OM} \downarrow$ & $\mathrm{P}$ concentration $\uparrow^{\mathrm{b}}, \mathrm{OM} \downarrow$ & $\mathrm{P}$ concentration $\downarrow, \mathrm{OM} \uparrow$ & P concentration $\uparrow, \mathrm{OM}_{\uparrow}$ & $\begin{array}{c}\text { Costs/ } \\
\left(\$ \mathrm{~kg}^{-1}\right)\end{array}$ \\
\hline Quartz sands & $+++^{\mathrm{c}}$ & + & ++ & + & $0.2-0.4[31]$ \\
\hline $\mathrm{AC}$ & + & +++ & + & + & $0.6-0.8[10]$ \\
\hline Zeolite & + & ++ & +++ & +++ & $0.9-1.6[38]$ \\
\hline Ceramic & + & ++ & ++ & ++ & $0.4-0.7[38]$ \\
\hline Furnace slag & + & +++ & + & ++ & $0.8-1.7[10]$ \\
\hline
\end{tabular}

$\downarrow \downarrow$ : relatively low concentration.

$\mathrm{b} \uparrow:$ relatively high concentration.

c + : the number of "+" shows the feasibility of the substrate for treatment of certain wastewater.

were also impacted by $\mathrm{OM}$ by influencing the $\mathrm{pH}$. The substrates that contained higher $\mathrm{Fe}$ and $\mathrm{Al}$ contents and lower $\mathrm{Ca}$ contents should be chosen (e.g., zeolite) when the $\mathrm{OM}$ concentration in the wastewater is high.

\section{The Proper Principles \\ for Selecting Substrates}

According to the $\mathrm{P}$ adsorption capacities of the tested substrates and the impact of the specific surface area and grain size, and $\mathrm{Ca}, \mathrm{Mg}, \mathrm{Fe}, \mathrm{Al}$, and $\mathrm{OM}$ contents on the $\mathrm{P}$ sorption capacities of these substrates we investigated, the proper principles for selecting substrates should be as follows. 1) For treatment of wastewater with simultaneous low $\mathrm{P}$ concentration and low OM, substrates with a low cost (for example, the quartz sands) should be chosen; 2) for treatment of wastewater with a high $\mathrm{P}$ concentration and low OM, substrates with a high P sorption capacity and relatively low cost should be chosen (OM accumulation resistance of the substrates does not have to be considered); 3) for treatment of wastewater with a low P concentration and high $\mathrm{OM}$, only $\mathrm{OM}$ accumulation resistance and the cost of the substrates should be considered; and 4) for treatment of wastewater with simultaneous low high $\mathrm{P}$ concentration and high $\mathrm{OM}$, substrates with high $\mathrm{P}$ sorption capacities and high OM accumulation resistance of the substrates should be considered (for example, zeolite and ceramic). The evaluation for proper use of the tested substrates is shown in Table 6 , which provides a qualitative analysis for the selection process for substrates used for the treatment of wastewater with different characteristics. Thus, additional studies should be conducted to quantify the exact concentration range of $\mathrm{P}$ and $\mathrm{OM}$ suitable for different substrates.

\section{Conclusions}

We tested and evaluated $\mathrm{P}$ sorption properties of four quartz sands with different physicochemical characteristics and four substrates commonly used in CWs. Our results support the following conclusions:
1) The P sorption capacity decreased as follows: furnace slag $>$ ceramic $>$ zeolite $>$ AC $>$ quartz sands (IV $>$ I $>$ II $>$ III), and the P adsorption capacities were correlated with the physicochemical characteristics of certain substrates.

2) The chemical precipitation of $P$ by the substrates containing Fe was more effective than those containing $\mathrm{Ca}$ at the same content.

3) $\mathrm{OM}$ affects $\mathrm{P}$ adsorption of the substrates by influencing $\mathrm{pH}$, and the substrates containing higher $\mathrm{Fe}$ and $\mathrm{Al}$ concentrations and lower $\mathrm{Ca}$ concentrations were more resistant to decreases in the $\mathrm{P}$ adsorption capacity due to the accumulation of OM.

4) Suitable substrates should be chosen for certain wastewater according to $\mathrm{P}$ sorption capacity, OM accumulation resistance, and cost.

5) Further study should be conducted to quantify the exact concentration range of $\mathrm{P}$ and $\mathrm{OM}$ that are suitable for different substrates.

\section{Acknowledgements}

This work was supported by the National Natural Science Foundation of China (No. 51268012) and Gan-Po 555 Programing for Top-Notch Personnel in Engineering (No. S2013-57).

\section{References}

1. TAO M., HE F., XU D., LI M., WU Z.B. How Artificial Aeration Improved Sewage Treatment of an Integrated Vertical-Flow Constructed Wetland. Pol. J. Environ. Stud. 19, 183, 2010.

2. KADLEC R.H. Comparison of Free Water and Horizontal Subsurface Treatment Wetlands. Ecol. Eng. 35, 159, 2009.

3. LI D., ZENG Q., LU Y., DENG S. Experimental Study on Sewage Treatment with Ecological Pond for Northern Railway Stations and Depots in Winter. China Railw. Sci. 35, 129, 2014.

4. KYNKÄÄNNIEMI P., ULÉN B., TORSTENSSON G., TONDERSKI K.S. Phosphorus Retention in a Newly 
Constructed Wetland Receiving Agricultural Tile Drainage Water. J. Environ. Qual. 42, 596, 2013.

5. VYMAZAL J. Constructed Wetlands for Wastewater Treatment: Five Decades of Experience. Environ. Sci. Technol. 45, 61, 2011.

6. XU G., SUN J.N., SHAO H.B., CHANG S.X. Biochar had effects on phosphorus sorption and desorption in three soils with differing acidity. Ecol. Eng. 62, 54, 2014.

7. ZHANG D.Q., JINADASA K.B.S.N., GERSBERG M.R., LIU Y., NG W.J., TAN S.K., Application of constructed wetlands for wastewater treatment in developing countries A review of recent developments (2000-2013). J. Environ. Manage. 141, 116, 2014.

8. LU S., ZHANG P., XIANG C. Phosphorus Removal by Constructed Wetland Treating Agricultural Runoff in Dianchi Region of China. Chin. J. Geochem., 25, 258, 2006.

9. WU S., KUSCHK P., BRIX H., VYMAZAL J., DONG R. Development of Constructed Wetlands in Performance Intensifications for Wastewater Treatment: a Nitrogen and Organic Matter Targeted Review. Water Res. 57, 40, 2014.

10. XU D., XU J., WU J., MUHAMMAD A. Studies on the Phosphorus Sorption Capacity of Substrates Used in Constructed Wetland Systems. Chemosphere 63, 344, 2006.

11. ZHANG D.Q., JINADASA K.B., GERSBERG R. LIU M.Y., TAN S.K. Application of Constructed Wetlands for Wastewater Treatment in Developing Countries-A Review of Recent Developments (2000-2013). J. Environ. Manage. 141, 116, 2014

12. WAN Z.F., ZHANG X.Q., LU S.Y. The Adsorption and Desorption of Phosphorus by Nineteen Constructed Wetland Substrates. Technol. Water Treat. 41, 35, 2015.

13. FERRO-GARCÍA M.A., CARRASCO-MARÍN F., RIVERA-UTRILLA J., UTRERA-HIDALGO E., MORENO-CASTILLA C. The Use of Activated Carbon Columns for the Removal of Ortho-Phosphate Ions from Aqueous Solutions. Carbon 28, 91, 1990.

14. ZENG Q., LI D., LU Y., DENG S., ZHU S., YANG R. Studies on Treatment of Domestic Wastewater by Enhanced Constructed Wetland in the Winter Northern. Technol. Water Treat. 40, 99, 2014.

15. LEI J., CHEN F.R., TANG Y., HAUPTFLEISCH K. Study on Characteristics of Phosphorus Adsorption by Using Four Types of Mineral Materials. J. Anhui Agricult. Sci. 43, 237, 2015.

16. CAN M.Y., YILDIZ E. Phosphate Removal from Water by Fly Ash: Factorial Experimental Design. J. Hazard. Mater. 135, 165, 2006.

17. LI Y., LIU C., LUAN Z., PENG X., ZHU C., CHEN Z., ZHANG Z., FAN J., JIA Z. Phosphate Removal from Aqueous Solutions Using Raw and Activated Red Mud and Fly Ash. J. Hazard. Mater. 137, 374, 2016.

18. WOLDE Z HAILE W. Phosphorus sorption isotherms and external phosphorus requirements of some soils of southern Ethiopia. Africa Crop Sci. J. 148, 89, 2015.

19. ELJAMAL O., OKAWAUCHI J., HIRAMATSU K., HARADA M., Phosphorus sorption from aqueous solution using natural materials. Environ. Earth Sci. 68, 859, 2013.

20. MITTAL A., KURUP L., MITTAL J. Enhancement of phosphorus sorption onto light expanded clay aggregates by means of aluminum and iron oxide coatings. Chemosphere 93, 1879, 2013.

21. TANG Q.Y., FENG M.G. Dps Data System and Operating Platform. Agriculture Press of China, Beijing, 1997.

22. HUANG L.D., QIU W., XU X.F., ZHANG Y.S. Opposite response of phosphorus sorption to $\mathrm{pH}$ and ionic strength: a comparative study in two different shallow lake sediments. Soil Sci. Plant Anal. 29, 519, 2013.

23. BAKER J.F., ANDERSON D.S., URNS R.T., MOODY L.B. The Use of Phosphorus Sorption Isotherms to Project Vegetative Treatment Area Life. Transactions of the ASABE 56, 935, 2013

24. ZHANG C., TAN S., LI J., PENG C. Polishing of Secondary Effluent by a Two-Stage Vertical-Flow Constructed Wetland. Pol. J. Environ. Stud. 24, 923, 2015.

25. CHEN J., KONG H., WU D., HU Z., WANG Z., WANG Y. Removal of Phosphate from Aqueous Solution by Zeolite Synthesized from Fly Ash. J. Colloid Interface Sci. 300, 491, 2006.

26. DALY K., STYLES D., LALOR S., WALL D.P. Phosphorus sorption, supply potential and availability in soils with contrasting parent material and soil chemical properties. Eur. J. Soil Sci. 66, 792, 2015.

27. GENZ A., KORNMÜLLER A., JEKEL M. Advanced Phosphorus Removal from Membrane Filtrates by Adsorption on Activated Aluminium Oxide and Granulated Ferric Hydroxide. Water Res. 38, 3523, 2004.

28. LI H.B., XIE F.Z., XUAN H., SHENG D.D., HU T.T., WANG C.X., XIE Z.Y. Phosphate Removal by Using Magnesium Oxide/Construction Waste of Subway Composite Ceramsite. Appl. Chem. Ind. 44, 1581, 2015.

29. WANG Y., YU Y., LI H., SHEN C. Comparison study of phosphorus adsorption on different waste solids: Fly ash, red mud and ferric-alum water treatment residues. J. Environ. Sci. [In Press] doi:10.1016/j.jes.2016.04.025, 2016.

30. LIDE D.R. Handbook of Chemistry and Physics. 90th ed. CRC Press, Boca Raton, FL, 2009.

31. DEL BUBBA M., ARIAS C.A., BRIX H. Phosphorus Adsorption Maximum of Quartz sands for Use as Media in Subsurface Flow Constructed Reed Beds as Measured by the Langmuir Isotherm. Water Res. 37, 3390, 2003.

32. WENDLING L.A., BLOMBERG P., SARLIN T., PRIHA O., ARNOLD M. Phosphorus sorption and recovery using mineral-based materials: Sorption mechanisms and potential phytoavailability. Appl. Geochem. 37, 157, 2013.

33. SOINNE H., HOVI J., TAMMEORG P., TURTOLA E. Effect of biochar on phosphorus sorption and clay soil aggregate stability. Geoderma s219, 162, 2014.

34. NGUYEN L.M. Organic Matter Composition, Microbial Biomass and Microbial Activity in Gravel-Bed Constructed Wetlands Treating Farm Dairy Wastewaters. Ecol. Eng. 16, 199, 2000.

35. MAHER C., NEETHLING J.B., MURTHY S., PAGILLA $\mathrm{K}$. Kinetics and capacities of phosphorus sorption to tertiary stage wastewater alum solids, and process implications for achieving low-level phosphorus effluents. Water Res. 85, 226, 2015

36. CHRISTOPH P., KLAUS M. Soil Clogging in Vertical Flow Reed Beds-Mechanisms, Parameters, Consequences and Solutions. Water Sci. Technol. 35, 175, 1997.

37. DEBICKA M., KOCOWICZ A., WEBER J., JAMROZ E. Organic matter effects on phosphorus sorption in sandy soils. Arch. Agron. Soil Sci. 62, 1, 2015.

38. GRAY S., KINROSS J., READ P., MARLAND A. The Nutrient Assimilative Capacity of Maerl as a Substrate in Constructed Wetland Systems for Waste Treatment. Water Res. 34, 2183, 2000.

39. DENG S., LI D., YANG X., ZHU S., LI J. Process of nitrogen transformation and microbial community structure in the $\mathrm{Fe}(0)$-carbon-based bio-carrier filled in biological aerated filter. Environ. Sci. Pollut. Res. 23, 6621, 2016. 